\title{
Correction to: Blockchain Adoption Intention in Higher Education: Role of Trust, Perceived Security and Privacy in Technology Adoption Model
}

Nishant Kumar, Mitushi Singh, Kamal Upreti, and Divya Mohan

\author{
Correction to: \\ Chapter "Blockchain Adoption Intention in Higher Education: \\ Role of Trust, Perceived Security and Privacy in Technology \\ Adoption Model" in: M. Al-Emran et al. (Eds.): \\ Proceedings of International Conference on Emerging \\ Technologies and Intelligent Systems, LNNS 299, \\ https://doi.org/10.1007/978-3-030-82616-1_27
}

The affiliation "Inderprastha Engineering College, Ghaziabad, India" of the author "Kamal Upreti" in the original version of the book has been removed from the chapter "Blockchain Adoption Intention in Higher Education: Role of Trust, Perceived Security and Privacy in Technology Adoption Model". The correction book has been updated with the change. 